\title{
Losing A Language: A Qualitative Study of Code-Switching Among Taiwanese-Chinese Bilingual Aphasic Speakers with Selective Recovery Pattern
}

\author{
Jui-Hua Chen, Ph.D. \\ Department of Foreign Languages and Literature \\ National Sun Yat-Sen University, 70 Lienhai Rd., Kaohsiung 80424, Taiwan \\ juihua@mail.nsysu.edu.tw
}

\begin{abstract}
This study aimed to investigate whether Taiwanese-Mandarin bilingual aphasia with selective recovery patterns lose knowledge of the inaccessible language or the control of the language they speak. Four patients were requested to narrate pictures in two separated language settings. The speech data collected in the clinical setting were compared with ten healthy bilingual adults' speech data. The healthy bilingual adults did not code-switch in L2 but L1, which may be due to the language shift phenomenon in their lives. There were quantitative and qualitative differences of code-switching between the two groups. For the quantitative differences, the greater amount of code-switching observed in patients indicated that they did not lose knowledge of the inaccessible language, but rather the control of the language they spoke, and this may result from the impairment of the control mechanisms. Also, for the qualitative differences, the healthy adults code-switched more on nouns than verbs because those were frequently-used nouns in $\mathrm{L} 2$, and there were no equivalent translations in $\mathrm{L} 1$; on the contrary, the patients code-switched more on verbs than nouns and this may be due to the mapping word and referent is less transparent for verbs than it is for concrete nouns.
\end{abstract}

Indexing terms/Keywords: code-switching; bilingual aphasia; selective recovery pattern

\section{INTRODUCTION}

Linguists' interest in bilingual aphasia is growing since the various recovery patterns of bilingual aphasia can lead linguists to explore language processing and language storage. At present, it is widely known that the most common recovery pattern is that bilingual aphasia's two languages are restored to the same degree. However, one of the relatively rare patterns is that bilingual aphasia disproportionately restore both languages. This phenomenon allows researchers to initially assume that each language is stored in a different brain area and the damage of a specific brain area will cause the loss of a language. However, some studies (e.g., Perani et al., 1996; Chee et al., 1999) using the brain image technology had shown that some common brain areas are activated when a bilingual speaker speaks two different languages, and this leaves the account for differential recovery in bilingual aphasia remains unclear.

Code-switching is a linguistic phenomenon occurs in bilingual or multilingual communities where people mix more than one language in a communicative setting. In Taiwan, bilingual or multilingual speakers are the norm. Most people are bilinguals of Mandarin and Taiwanese, Mandarin and Hakka, or Mandarin and minority languages, for example, aboriginal languages (Kubler, 1988). The greatest majority of bilingual speakers are those speak Mandarin and Taiwanese (Huang, 1993). Therefore, those who suffer from acquired language disorders in Taiwan are most likely to be bilingual aphasic speakers of Mandarin and Taiwanese.

The present study aims to investigate if selective recovery bilingual aphasic patients code-switch in the picturenarrating context. If bilingual aphasics lose the one of the language knowledge, the codeswitching phenomena will not appear in his/her narrative context. In contrast, if the codeswitching occurs in their speech, it may prove that they do not lose the knowledge of the inaccessible language but the control. Also, whether or not the codeswitching that the bilingual aphasics provided in the context is similar to that appeared in the healthy bilingual speakers' narrative context? 


\section{LITERATURE REVIEW}

\subsection{Six Types of recovery pattern in bilingual aphasia}

Paradis (1977), based on the review of the literature on bilingual and polyglot aphasia and described six patterns of recovery: parallel, differential, successive, antagonistic, selective and mixed (or blended). Parallel recovery two (or all) languages are equally damaged and recover at the same rate. Difference recovery - languages are restored in different ways relative to their premorbid level. Successive recovery - when one language is restored to its optimum level, another language begins to reappear. Antagonistic recovery - a language progression is accompanied by another language regression. Selective recovery - only one of the languages recovers. Blended/ mixed recovery - a systematic and inappropriate blend or a mixture of languages for patients at any or all levels of the linguistic structure.

These patterns are not mutually exclusive, either over time or between languages. For example, successive recovery may be followed by reciprocal antagonism or two languages may be recovered in a parallel or antagonistic fashion while a third remains inaccessible or is recovered only much later (Paradis, 1977).

\subsection{Accounts for differential recovery in bilingual aphasia}

Ribot's Law. Ribot (1882) described the retroactive phenomena of trauma or even-induced memory loss in his book "Diseases of Memory: An Essay in the Positive Psychology". The patients who suffered from amnesia after an accident or a trauma often lost memory of the event and the several years leading up to the incident. The patients' earlier memories (including languages they spoke at their early ages) are conserved much more consolidated than their latest memories. In the late 1700s, some studies of bilingual aphasia whose two languages recovered differently also supported the greater strength of early memories. In some cases, aphasics recover or preferentially improve only the first-acquired language (L1), although this seems only happened mostly in people who never indeed spoke their second language fluently. (Pearce, 2005).

Pitres' Law. Ribot's law (1882) claimed that the patient's newly learned language is better preserved than the earlier acquired language (Lorch, 2009). In contradictory, Pitres (1895) described seven patients and found the different recovery in their two languages. He assumed that the patients' most familiar language before the disease is often better preserved or restored earlier.

Localizationist. Linguists have proposed various theoretical explanations for the differential language recovery patterns in bilingual aphasia. Early researchers found that the language disorders of some bilingual aphasic patients manifested differently in the degree of the severity, and concluded that because a different brain region or even a different brain hemisphere is responsible for each language, it will cause the loss of a specific language when a specific brain area is damaged. This theory is called the "localizationist" (Albert, 1978). Scoresby-Jackson (1867) further hypothesized that Broca's area would be only in charge of the native languages and that the region around Broca's area would be in charge of the L2s (Lorch, 2007).

For more than a century, the localizationist theory has remained dominant in neurolinguistics, especially in explaining the functioanl neuroimaging data of bilinguals (Abutalebi, 2009). However, at present, neurolinguists still have different views on the localizationist theory. Perani et al. (1996) used PET to observe an Italian-English bilingual aphasic and found that his L1 (Italian) activated more in the perisylvian area, such as inferior frontal gyrus, superior and middle temporal gyrus, temporal pole, angular gyrus, and right cerebella, while his L2 (English) activated more in the right and left superior and middle temporal gyrus and parahippocampus. However, Chee et al. (1999) observed the brain activation of a Mandarin-English bilingual aphasic and found no difference between these two languages. They reported that both languages activated inferior frontal, dorsolateral frontal, temporal, parietal and right cerebella. Therefore, Chee et al. proposed the opposite opinion from Perani et al. (1996) and stated that both L1 and L2 activated the same brain areas. 
The rejection of the 'localizationist' account drove some researchers to find an alternative account for the selective recovery in bilingual aphasia. They accounted for the selective recovery pattern in bilingual aphasics by various models of language representation and control.

Language control mechanism. One of the current theories about why a language of bilingual aphasia recovers better than another suggests that this happens when a stroke damages a specific control mechanism in the brain. Because a bilingual speaker knows two languages, when he/she is using a language, other languages that are not used must be suppressed or "switched off." If the mechanism controlling the switch is impaired, one of the languages of the bilingual aphasic patients may no longer be able to recover to the same extent. Because the ability to control the 'switch' has been lost and the patient may not be able to 'switch on' one of the not-inused languages, he/she will lose that language forever. On the surface, the patient seems to be losing the language, but in reality, the patient loses the ability to control the switch mechanism of the language. (Green, 1986; Green, 1998; Abutalebi \& Green, 2007; Green \& Abutalebi, 2008).

ATH (Activation Threshold Hypothesis). To account for the differential recovery in multilingual aphasia, Paradis $(1985 ;$ 1993) proposed the activation threshold hypothesis (ATH). He believes that the threshold of a language item will vary depending on the frequency of use and the frequency of the item itself. The higher the frequency of the language item, the lower the activation threshold will be so that the item will be extracted faster and easier. Less activated language items will require more stimulations than frequently activated items to be reactivated. In other words, when a particular language item has a high activation threshold, more activation impulses are needed to reactivate it (Gürel, 2004). Therefore, bilinguals control the switch of different languages in the brain through the mechanisms of inhibition and activation. When one language is activated, another language is inhibited. This means that the activation threshold for the unselected language is increased so that it will not be activated (Gürel, 2004).

It should be noted that this does not mean that the one of the bilingual speaker's language system is completely lost because of the suppression or activation threshold (Green, 1986). Even different activation thresholds do not appear in different languages. Depending on the frequency of use, different language items in the same language may require different degrees of stimulation to be activated (Paradis, 1997).

Other accounts. Various factors such as language acquisition age, language proficiency, language use, and language structure are used to explain the "differential recovery" model in bilingual or multilingual aphasia. For example, Fabbro (2001) suggests that the age of language acquisition (early or late) affects the cortical area that is activated when the language is used. He suggested both early and late bilingual speakers activated similar brain areas in two languages when they used lexical items, but late bilinguals activated a different brain area when they used grammatical structures in two languages. Also, Klein (1999) provides evidence that the level of language proficiency is critical for brain activation patterns (e.g., cerebral blood flow) in language tasks. When L1 and L2 are equally proficient, these two languages may activate similar brain regions. Paradis (1995) stated that language structures affect the grammatical disorders in aphasia, not just vocabulary. He indicated that bilingual aphasic patients would have similar grammatical disorders in both languages that have similar language structure, but the different grammatical disorder would only occur in the languages which have different language structure (Paradis, 1995).

Therefore, the language background of ten bilingual aphasic patients investigated in the present study was documented in detail in order to further explore the possible variables which may affect patients' recovery patterns.

\subsection{Code-switching in bilingual aphasia}

Although various theories have been proposed to account for the switch of languages in the brain (Green, 1986; Paradis, 1993), we still lack satisfactory explanations of whether bilingual aphasic speakers process the languages in the same way as neurologically healthy bilinguals do and how those languages interfere with each other. 
Code-switching behaviour observed in bilingual or polyglot speakers have attracted linguists' attentions recently since the study of code-switching may shed light on how people process speech and how they switch languages without effort. Because language mixing is a frequently observed recovery pattern in bilingual aphasics (Junque, 1989; Paradis, 1995), by observing code-switching behaviour produced by aphasic speakers, more evidence will be provided to account for the process of speech production.

Perecman (1984) observed the code-switching and spontaneous translation behaviors of an 80-year-old bilingual male with a bilateral temporal lobe hematoma caused by a car accident. In her research, she used the word "language mixing" to represent code-switching. She stated that when language mixing occurs at the utterance level, it indicates a linguistic deficit, and spontaneous translation indicates prelinguistic processing deficits. However, Grosjean (1985) disagreed with these findings and pointed out that the code-switching of the utterance level is not unique to bilingual aphasia. He further pointed out that the interlocutor in Perecman's (1984) study is a multilingual speaker who may trigger language mixing as a communicative strategy in the bilingual aphasic patient's context. It is because that bilingual aphasia, as well as healthy bilingual speakers, need to alternate the use of the language for being an appropriate contextual language, and sometimes lack of linguistic competence may affect the ability to change language code (Muñoz, 1998).

Some studies (e.g., Hyltenstam, 1995; Muñoz et al., 1998; Chengappa et al., 2004) compared the code-switching patterns between healthy bilingual adults and bilingual aphasia and concluded that there was an increase in the quantity of code-switching in bilingual aphasics and no qualitative differences in the type of code-switching among healthy adults and aphasics. The more significant amount of code-switching appears in the corpus of bilingual aphasic patients, which means that bilingual aphasic patients rely on the use of two languages as a compensation strategy to increase communicative effectiveness. In addition, Bhat and Chengappa $(2003,2005)$ found that Kannada-English bilingual aphasia and healthy bilinguals code-switched more in the first language. Because the language all the participants used more often in their adult life is English and even the aphasic patients used English frequently after the onset of morbidity, they concluded that the second language of the bilingual speakers the takes over the first language. In other words, the frequent use of a second language over a long period of adulthood could make the bilingual speakers' second language more accessible. This phenomenon is known as language shift.

By looking back at cases about multilingual aphasia recovery patterns published over the end of the $19^{\text {th }}$ century and early $20^{\text {th }}$ centuries, Paradis $(2009, \mathrm{p} .172)$ postulates that in some cases in which 'the native language is significantly less well recovered than a language that was learned formally later, in which individuals are likely to have considerable metalinguistic knowledge to fall back on'. Paradis further explained that 'the reliance on metalinguistic knowledge will be more likely in cases when (1) the second language was learned formally or (2) the second language was the language of instruction and the patient was not schooled in his or native language, especially when the native language is a spoken dialect' (Paradis, 2009, p.172).

\section{MATERIALS AND METHODS}

\subsection{Participants}

The bilingual aphasic patients were referred for this study by a speech therapist in the Department of Rehabilitation, Kaohsiung Medical University Chung-Ho Memorial Hospital where they were receiving ongoing speech rehabilitation services. Various criteria were used to identify those patients who were to be included in the study. First, the patient had to be at least six months post-onset of illness to ensure that they had passed the early acute phase of recovery. Second, the subjects had to be moderately rather than severely impaired, which may have involved dysarthric difficulties, nor too mild, which would have produced little analysable divergent. Thirdly, they needed to have a known history of bilingualism.

For assessing the language history and usage patterns of aphasic patients, a questionnaire used in the Muñoz (1999) study to compare the code-switching patterns of English-Spanish aphasics and neurological normal 
bilingual speakers was used in this study. The questionnaire was divided into three sections: (1) family history, (2) language history and (3) language use. Because the present study was undertaken in Taiwan, the questionnaire has been translated into Chinese.

The four aphasic patients selected for the present study were bilingual speakers of Taiwanese and Mandarin before their neurological illness. All subjects were assigned initial names to protect their identities. However, it should be noted that although the aphasic patients were given the Mandarin version of the Boston Diagnostic Aphasia Examination (BDAE) (Goodglass \& Kaplan, 1972), due to data protection regulations, no access was given to standardised test results or neurological diagnostic images. However, the focus of the present study is an exploration of the linguistic manifestations of bilingual aphasic speakers of Taiwanese and Mandarin. No discussion of the relationship between particular linguistic impairments and lesion localisation will be carried out.

The four bilingual aphasic patients were classified into the group with selective recovery based on Paradis' (1977) classification of language recovery patterns of bilingual aphasia. Patient data is presented in table1.

Table1. Patient Data

\begin{tabular}{|l|c|c|c|c|c|c|l|l|}
\hline No. & Name & Gender & Age & $\begin{array}{l}\text { Edu. } \\
\text { (years) }\end{array}$ & L1 & L2 & Response in & Response in \\
Mandarin task & Taiwanese task \\
\hline 1 & WL & M & 42 & 12 & Taiwanese & Mandarin & Mandarin & NO \\
\hline 2 & HQ & M & 62 & 12 & Taiwanese & Mandarin & Mandarin & NO \\
\hline 3 & LQ & M & 59 & 14 & Taiwanese & Mandarin & NO & Taiwanese \\
\hline 4 & XS & M & 55 & 6 & Taiwanese & Mandarin & NO & Taiwanese \\
\hline
\end{tabular}

\subsection{Materials}

Two sets of tasks were used to elicit speech samples from both the patients and the controls. The first task was the description of complex action pictures. The second elicitation task was based on the Wechsler-Bellevue sequences of pictures representing narratives. All the pictures are from Menn and Obler (1990).

Description of complex action pictures. The first task was a description of the complex pictures full of action. BDAE "Cookie Theft" and "Family Gathering" were used as stimulus pictures for those patients and the controls for whom it was culturally appropriated. The "Family Gathering" picture was used by a Japanese team (Sasanuma, 1990) in Menn \& Obler (1990), and it was selected for this study due to the similarity of the cultural background between Taiwanese and Japanese.

Wechsler-Bellevue sequences of pictures. The second elicitation task was based on the Wechsler-Bellevue sequences of pictures representing narratives. Four modified Japanese versions of the Wechsler-Bellevue Picture Sequences (Sasanuma, 1990) were selected and narratives concerned: (1) a farmer was planting and harvesting a grain crop, (2) a thief was arrested by the police during the robbery, (3) a dog stole a picnicking couple's meal, and (4) a boy was refusing to bring an umbrella and getting wet in the rain on his way to school. All six pictures used in this study were extracted from Menn \& Obler's (1990) research in order to compare the results with previous studies. 


\subsection{Procedure}

Grosjean (1982) proposed the concept of "language mode," which is the activation state of the language processing mechanism of bilingual speakers. He pointed out that bilinguals usually unconsciously choose which language to use and how many other languages they need. Another language that has not been selected will be inhibited. On the other hand, if another language is needed, it will be activated, but the activation level will be lower than the main language which has been using. Grosjean (1982) described that a bilingual speaker's language mode could be in a continuum depending on his/her situation. On the one hand, they may be in monolingual mode, ideally without mixing, and on the other hand, they find themselves in a bilingual mode where they mix languages freely. The changes of the bilingual speakers' situations may result in their different language behaviours. Therefore, bilinguals will change the language used depending on the time, the interlocutors and the situations they are in. It is necessary to control the 'language modes continuum' in the study of bilingualism. Ideally, it is recommended to evaluate bilingual speakers' monolingual mode and bilingual mode on different days with different interlocutors. In this study, attempts have been made to do so.

All the patients were requested to describe and narrate pictures in two separate sessions; one exclusively in Mandarin and the other exclusively in Taiwanese. This monolingual mode of elicitation was used in order to limit the potential for interference between the two languages (Grosjean, 2001) and to minimize fatigue by limiting the length of the session. The aphasic patients' speech was audio recorded in a speech therapy room in Kaohsiung Medical University Chung-Ho Memorial Hospital.

All the neurologically healthy controls were requested to describe all six pictures in two languages respectively, and the speech data was audio recorded in a quiet room with only the subject and the interviewer present in the self-study room of Kaohsiung Cultural Center library.

\subsection{Transcription}

Interlinear morphemic transcriptions following the guidelines established by Menn and Obler (1990, p.17-24) were provided for each narrative, focusing on morphology, syntax and errors of lexical choice in order to make the grammatical structure of the original language text transparent. The example of the presentation of the interlinear morphemic transcription in this study is illustrated below.

\section{Line 1, corrected or expected forms}

Line 2, patient's morphemes

\section{Line 3, morphemic translation}

\section{Line 4, English equivalent of line 2}

x̌̌wăn

[Ta] hăoxiàng zài *zhǔcài

[she] seems ASP cooking

It seems like [ ] was cooking

The second line (line 2) of the set of four is primary, presenting the patient's output. In line two, omitted words are supplied, enclosed in brackets [ ]. When a form in line two is the wrong one (a substitution error) or an unexpected form, it is marked with an asterisk * and the corresponding corrected form is displayed in line one, above the error. Line three, gives a morpheme by morpheme English translation of line two and provides grammatical labels. Line four of the interlinear morphemic translation gives an English approximation of the grammatical quality of the patient's output. Thus, in general, if a morpheme was omitted in the original line two, its English counterpart is omitted on line four, and if there is a substitution error in the original, a similar substitution is made in English, if at all possible.

Code-switching words or phrases will be examined and enclosed in curly brackets \{\} . For example, line one presents the patient's output and the code-switching words chúi, 'water' and pháin-khì, 'broken' were enclosed 
in curly brackets \{ \}. Line two gives a morpheme by morpheme English translation, and line three gives the English equivalent translation of line one.

Line 1, patient's morphemes Zhègè \{chúi\} nàgè \{chúi\} $\quad{ }^{*}\left\{\right.$ pháin $\left.{ }^{\mathrm{n}}-\mathrm{khi}\right\}$

Line 2, morphemic translation This-CL.water that-CL. water bad go

Line 3, English equivalent of line 1 This water...that water...broken

In addition, the code-switching words produced by the aphasics will be analysed by the grammatical categories (such as noun, verb and function words) and compared with those produced by the controls.

\subsection{Transcription reliability}

All speech data collected from ten bilingual aphasic patients and ten healthy bilingual speakers were transcribed separately by the author and the speech therapist who worked in the Department of Rehabilitation, Kaohsiung Medical University Chung-Ho Memorial Hospital. The two sets of transcriptions were compared to identify discrepancies. Only 14 out of a total of 491 words (2.8\%) were found in the transcriptions of the Mandarinspeaking aphasic patient corpus while there were 7 out of a total of 371 words (1.9\%) found in the Taiwanese speaking patient transcriptions. There were 128 out of a total of 4923 words (2.6\%) which were transcribed differently in the healthy Mandarin speakers' transcriptions while there were 86 out of 4037 words (2.1\%) which were discrepant in the healthy Taiwanese speakers' transcriptions. Overall the differences in the two transcriptions were represented less than $3 \%$ of the data. All the discrepancies were discussed by the two transcribers. After the discussion, the transcriptions were revised by consensus between the author's and the speech therapist's agreements.

\section{RESULTS}

\subsection{Distribution of grammatical categories in narratives}

Table2. Distribution of all patients' and controls' grammatical categories in narratives

\begin{tabular}{|l|c|c|c|c|c|c|}
\hline & \multicolumn{4}{|c|}{ Aphasic } & \multicolumn{2}{c|}{ Healthy } \\
\hline & \multicolumn{2}{|c|}{ Mandarin } & \multicolumn{2}{c|}{ Taiwanese } & Mandarin & Taiwanese \\
\hline & WL & HQ & LQ & XS & MEAN & MEAN \\
\hline Noun & 36 & 49 & 40 & 64 & 81 & 75 \\
\hline Verb & 33 & 72 & 60 & 63 & 119 & 114 \\
\hline Stative V. & 0 & 1 & 3 & 2 & 10 & 5 \\
\hline Adjective & 0 & 0 & 0 & 0 & 7 & 2 \\
\hline Adverb & 9 & 18 & 8 & 8 & 79 & 39 \\
\hline Determiner & 43 & 10 & 5 & 7 & 9 & 5 \\
\hline Number & 0 & 9 & 0 & 0 & 15 & 12 \\
\hline
\end{tabular}




\begin{tabular}{|l|c|c|c|c|c|c|}
\hline Classifier & 42 & 18 & 3 & 2 & 23 & 17 \\
\hline Pronoun & 12 & 10 & 3 & 9 & 41 & 41 \\
\hline Preposition & 1 & 9 & 1 & 9 & 28 & 17 \\
\hline Aspect & 1 & 18 & 7 & 8 & 14 & 14 \\
\hline Auxiliary & 5 & 5 & 8 & 7 & 12 & 5 \\
\hline Conjunction & 0 & 2 & 1 & 4 & 7 & 5 \\
\hline Negation & 12 & 10 & 5 & 6 & 9 & 10 \\
\hline Question & 12 & 1 & 0 & 0 & 1 & 0 \\
\hline Copula ${ }^{1}$ & 3 & 8 & 1 & 0 & 12 & 5 \\
\hline Ba/Ka & 2 & 0 & 3 & 3 & 4 & 7 \\
\hline Bei/Ho & 1 & 2 & 2 & 2 & 2 & 4 \\
\hline De/E & 1 & 1 & 4 & 5 & 16 & 25 \\
\hline SFP2 & 11 & 24 & 11 & 7 & 3 & 2 \\
\hline TOTAL & 224 & 267 & 165 & 206 & 492 & 404 \\
\hline
\end{tabular}

\subsection{Code-switching in all aphasic patients and the healthy controls}

Quantitative Result. Table 3 indicates that the healthy controls did not produce any code-switch in the Mandarin tasks. However, they produced 120 code-switching words in the Taiwanese tasks. In the Taiwanese task, they produced 74 nouns, 29 verbs and 17 function words in the not-in-use language (here, Mandarin). The code-switching in nouns occupied $61.7 \%$, verbs occupied $24.2 \%$, and the function words occupied $14.1 \%$ of all the code-switching behaviors. This result shows that the healthy controls code-switched more on the content words than on the function words and surprisingly they only code-switched when they narrated in their native language (Taiwanese), but not the dominant language (Mandarin).

WL. He produced 32 code-switching instances which occupied 14 percent of all the words he produced. WL produced more code-switching on content words than function words. Fifty-three percent of code-switching words were content words while about four-seven percent of words were function words. One interesting point is that WL produced 15 code-switching instances on verbs, which was 46.9 percent of all the code-switching words he produced. This is notably in contrast to the very few code-switches that occurred in the production of nouns. Of the function word code-switches, nine of these were on pronouns.

HQ. He produced 14 code-switching words, which represent five percent of all the words he produced. HQ's percentage of code-switching is relatively low compared with WL's percentage of code-switching words, but HQ's percentage may still be significant since none of the healthy controls produced code-switching in their

${ }^{1}$ Copula: a connecting word, in particular a form of the verb be connecting a subject and complement

${ }^{2}$ SFP: sentence-final particle, such as le, ne, ba, ou, $a, l a, y a, m a$ 
elicited speech. The largest category of code-switching in HQ's data is function words. When we examine WL's distribution of code-switching instances, we found that he also produced a high percentage $(46.9 \%)$ of codeswitching on function words.

LQ. He produced 12 code-switching words, which represent about seven percent of all the words he produced. LQ's percentage of code-switching was relatively high compared with the percentage of the healthy control group, which was $3.2 \%$ of all the words they produced. He produced code-switches on content words but not on function words. The largest category of code-switching is a verb, which was about sixty-seven percent of all the code-switching words he produced.

XZ. He produced six code-switching words (3.2\%) in the total of 206 words while the control group produced 13 code-switching words (2.9\%) in 404 words. Furthermore, XS produced five code-switching words on nouns (83.3\%) and only one word on stative verbs $(16.7 \%)$ while the ten healthy controls produced seventy-four codeswitching on nouns (61.7\%) and twenty-nine on verbs (24.2\%). Both XS and the control group produced more code-switching on nouns than on the other categories.

Like the previous studies, there was an increase in the quantity of code-switching in bilingual aphasics. By comparing the code-switching in the Mandarin context in two groups, the percentages of code-switching behaviours produced by two aphasic patients are significantly higher (WL, 14.3\% and HQ, 5.2\%) since the healthy adults did not code-switched in all Mandarin tasks. However, in Taiwanese context, only LQ produced significantly higher percentage $(7.3 \%)$ of code-switching than the healthy adults $(3 \%)$, and unexpectedly, XS produced equally percentage (2.9\%) of code-switching with the healthy adults. In other words, the patients with selective recovery pattern (except XS) exhibited much higher percentage of code-switching behaviours than those patients with parallel recovery pattern and normal adults.

Additionally, Table 3 shows that three aphasic patients produced greater amount of code-switching on verbs than on nouns. However, the healthy adults code-switched more on nouns.

The results may indicate that the code-switching observed in the Taiwanese-Mandarin bilingual aphasic patients exhibited not only the quantitative differences but also qualitative differences.

Table 3. Code-switching in all aphasic patients and the healthy controls

\begin{tabular}{|l|c|c|c|c|c|c|}
\hline & \multicolumn{4}{|c|}{ Aphasic } & \multicolumn{2}{c|}{ Healthy } \\
\hline & \multicolumn{2}{|c|}{ Mandarin } & \multicolumn{2}{c|}{ Taiwanese } & Mandarin & Taiwanese \\
\hline & WL & HQ & LQ & XS & ACTUAL & ACTUAL \\
\hline Noun & 2 & 3 & 4 & 5 & 0 & 74 \\
\hline Verb & 15 & 4 & 8 & 0 & 0 & 29 \\
\hline Stative Verb & 0 & 0 & 0 & 1 & 0 & 0 \\
\hline Functors & 15 & 7 & 0 & 0 & 0 & 17 \\
\hline Total & 32 & 14 & 12 & 6 & 0 & 120 \\
\hline
\end{tabular}

\footnotetext{
${ }^{3}$ Functors include numbers, classifiesr, pronouns, prepositions, aspect markers, auxiliaries, conjunctions, negations, questions, copula, ba/ka, bei/ho, dele, and sentence-final particles.
} 


\begin{tabular}{|l|c|c|c|c|c|c|}
\hline Percentage $^{4}$ & $14.3 \%$ & $5.2 \%$ & $7.3 \%$ & $2.9 \%$ & 0 & $3 \%$ \\
\hline
\end{tabular}

Qualitative Result. WL code-switched on seven out of eight main sentences. However, he only shifted to the not-in-use language on pronouns not nouns. In (1) WL used the pronoun I 'she/he' in Taiwanese, but he did not code-switch on the noun xiăopéngyǒu 'children' when he produced the same sentence structure 'subject + verb' (\{l kóng\} 'he say'; xiǎopéngyǒu \{kóng\} 'children say'). This may because xiǎopéngyǒu 'children' is a highfrequency word in Mandarin with no direct translation equivalent in Taiwanese. The code-switching on the word xiăopéngyǒu 'children' was commonly observed in our control group's speech corpus when they were asked to speak Taiwanese.

$$
\begin{aligned}
& \text { \{I kóng\} zhègè ...xiăopéngyǒu }\{\text { kóng\} ø bú yào nàgè xiàyŭ } \\
& \text { He say this-CL. Children say } \quad \text { (he) no want that-CL. down rain }
\end{aligned}
$$

He said...this child said that [he] did not need this * rain/umbrella.

$$
\text { Zhègè }\{\text { chúi }\} \ldots \text { nàgè }\{\text { chúi }\} \ldots<\left\{\text { pháin }{ }^{\mathrm{n}} \text {-khì }\right\}>
$$

This-CL.water that-CL. water bad go

This water...that water...broken.
Tā...tā ...nàgè
ā... \{chiáh-hun
la\}
$\mathrm{He}$ that-CL. EMP. eat tobacco SFP
He...he...that...smoking...

\section{Jinngchá \{tioh kā $\varnothing \quad$ lákkhílâi $\quad \bar{a}\}$}

Policeman then KA (he) arrest up come EXC.

$[\mathrm{He}]$ was then arrested by the policeman.

Except for producing code-switching on the verb kóng, 'say' seven times, the remaining verbs that WL codeswitched on are complex verbs; for example, pháin khì 'to break' in (2), chiáhhun 'to smoke' in (3) and lákkhílâi 'to arrest in (4). This observation may be interpreted as indicating that a word formation process deficit might cause WL's speech disorder.

$\boldsymbol{H Q}$. He code-switched a word or a phrase right after the word or the phrase he produced. For example, in (5), $\mathrm{HQ}$ said nàgè zào, 'that stove' in Mandarin and he then code-switched the noun zào,' stove' into Taiwanese chàu, 'stove' immediately. In (6), HQ produced a verb phrase in Taiwanese first and then he code-switched the verb phrase into Mandarin. HQ spontaneously translated the words or phrases, a type of behaviour described by Perecman (1984).

(5) Zhègè hăoxiàng yǐqián nàgè xiāngxià de nàgè zào.

This CL. Good likeness before that-CL. Village down ATR that-CL. stove

This looks like the stove that people used in the village.

\footnotetext{
${ }^{4}$ This presents the code-switching percentage of all the speech data produced by each patient.
} 
Nàgè $\quad\{$ chàu

that CL. stove

that stove

(6) \{the'h-chhut-lâi pha'k a\}

bring out come back EXC.

Bring out and dry in the sun.

[Na] chūqù shài $\bar{a}$ !

[bring] out go bask SFP

Bring out and dry in the sun

LQ. The information in Table 3 shows that LQ code-switched on content words but not on the function words. The largest category of code-switching in LQ's speech data was verbs, which was $66.7 \%$ of all the code-switching words. This was notably in contrast to the few code-switches that occurred in the production of nouns. In contrast, the largest category of code-switching in the control group's speech data was nouns, which was $61.5 \%$ of all the code-switching words. The high percentage in the noun category in the healthy control group's data was because they often code-switched on the nouns which were high-frequency words in Mandarin with no direct translation equivalent in Taiwanese. The code-switching on the words xiăopéngyǒu 'children' or bāobāo 'bag' was commonly observed in the control group's speech corpus when they were asked to speak Taiwanese.

Example (7) presents that LQ code-switched on the part of the preposition phrase and he code-switched on the main verb of this sentence.

\section{(7) Tī $\quad$ chúfang $\}$ gín-á lē $\quad$ wánshuǎ $\}$ \\ In kitchen child ASP play}

In the kitche children were playing...

In (8), LQ code-switched on the noun phrase mama 'mother' which is a high-frequency word in Mandarin. Not only did LQ code-switch on this word but also many of the ten healthy control adults.

(8) $\quad\{$ Mama $\}$ teh sé-óa ${ }^{\mathrm{n}}$

Mother ASP wash-bowl

Mother was doing the dishes

When LQ had difficulty initiating the sentence, the therapist asked him a question to elicit his speech. Example (9) presents that when the therapist asked him a question in Taiwanese which was the target language in the task, LQ responded with dădiànhuà 'to make a phone call' in Mandarin.

(9) E: In chéché leh chhòng-sián?

His sister ASP do Q-what

What did his sister do? 
LQ: $\quad$ Dădiànhuà $\}$

Hit electricity talk

Make a phone call.

Again, in example (10), when the therapist asked LQ a question in Taiwanese, he responded first with a verb phrase chéngtiū-á 'to plant rice' in Taiwanese. Then, he responded with two verb phrases shōuge 'to harvest' and bānyùn 'to carry' in Mandarin. The fourth utterance in (10) shows that LQ code-switched on the part of the verb predicate. He only code-switched on the main verb bānyùn 'to carry' and the nominal modification shōugē 'harvested' before the prenominal modification marker $e$. The noun mih-kiän 'things' which was modified by shōuge 'harvested' and the prenominal modification marker $e$ in the noun phrase, was preserved in Taiwanese. Example (11) also shows that LQ replied with a Mandarin word cāngkù 'warehouse' in the Taiwanese context.

E: Chit ê lâng leh chhòng-sián ?

This CL. Man, ASP do Q-what

What was this man doing?

LQ: Chéng tiū-á.

Plant rice

To transplant rice seedling.

\{Shōugē $\quad$ \{Bānyùn $\}$

Collect cut Move carry

To harvest To carry

\{Bānyùn $\}$ \{shōugē $\quad \overline{\mathrm{e}} \quad$ mih-kiā ${ }^{\mathrm{n}}$

Move carry collect cute thing-thing

To carry the things that were harvested.

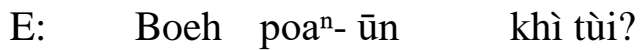

Want move carry go Q-where

Where did [he] carry [it] to?

S: $\quad$ C Cāngkù $\}$

Warehouse

Warehouse

Example (12) shows that LQ code-switched on the main verb jiäoyóu 'to go picnic' and example (13) shows that he code-switched on the part of the noun phrase bāobāo 'bag', which is a high-frequency word in Mandarin. 
(12) Chúlâng beh khì \{jiāoyóu \} la!

Master want go picnic EXC.

The owner is going to go picnic.

(13) Che káuá khòa ${ }^{\mathrm{n}}$-tio`h i sinkhu ê $\{$ bāobāo $\}$ ê mi hh-kiān

This dog look arrive he body e bag e thing

The dog saw the thing that was in the bag on his/her body.

Example (14) presents that XS code-switched the verb chāyāng 'transplanting rice' first, then he spontaneously translated the verb into the target language, Taiwanese, and produced pòchhân 'transplanting rice'.

Chit ê [lônghu] leh \{chāyāng\} pòchhân

This CL (farmer) Asp insert rice plant field

This (farmer) was transplanting rice seedling

Example (15) presents that XS code-switched the compound noun shübāo 'schoolbag'. It might be because that shübāo 'schoolbag' is a high-frequency word in Mandarin and the equivalent translation in Taiwanese is a lowfrequency word. The code-switching observed in examples (16) and (17) may indicate the frequency effect on word selection since the words XS code-switched were high-frequency words in Mandarin. These three highfrequency words, xiăopéngyǒu 'children, xiăogǒu 'dog' and didì 'boy or brother' were also found to be codeswitched by the control group often.

I ê $\left\{\right.$ shūbāo\}lāi-té $\varnothing$ mihkiân ${ }^{n}$ lutkhi a

He e bag inside (e) thing fall go SFP

The thing in his bag was missing

(16) \{Xiăopéngyǒu $\}$ beh chhutmn̂g

Children want out door

Children want to go out

(17) $\quad\{$ Xiăogǒu $\}$ ka \{dìdì $\}$ e chheh-phāin ${ }^{\text {-á }}$

Little dog bite boy e book carry

A dog bites boy's school bag

\section{DISCUSSIONS}

\subsection{Losing the knowledge or the control of a language.}

The four selective recovery bilingual patients (WL, HQ, LQ, and XS) code-switched in the tasks, although they were only able to respond in one language which was reported better recovered in the clinical settings, they still code-switched with their inaccessible language. For example, patients WL and HQ could only complete the 
tasks in Mandarin setting, but they occasionally produced some Taiwanese utterances in Mandarin contexts. In contrast, patients LQ and XS could only finish the tasks in Taiwanese settings, but they provided some Mandarin utterances in Taiwanese contexts. This result may indicate that bilingual aphasic patients with selective recovery pattern did not lose the knowledge of the language that exhibited less or not recovered. The code-switching found in the speech data of selective recovery bilingual aphasic patients provided evidence to support Pitres' (1895, cited in Chengappa, 2004) in which he claimed that language recovery failure was not due to the loss of language itself, but to the pathophysiological inhibitory effects.

\subsection{Code-switching patterns.}

There is no consensus on whether code-switching observed on bilingual aphasia is a pathological phenomenon or a natural phenomenon since neurological healthy bilingual adults often provide code-switching in their daily conversation settings, too (Chengappa 2004). Perecman (1984) observed the language mixing phenomenon and spontaneous translation phenomenon in a polyglot aphasic speaker's conversation and concluded that those behaviours were atypical of neurologically healthy bilingual speakers and indicated the language insufficiency of the multilingual aphasic speaker.

However, Grosjean (1985) commented on Perecman (1984) and argued that language mixing and spontaneous translation are not unique to the multilingual aphasic patients. Both of them were found in the neurological healthy multilingual speakers' speech; therefore, it can not be an indication of language deficits in aphasia. In order to compare the differences and similarities of the code-switching patterns between English-Spanish bilingual aphasic patients and neurological healthy adults, Muñoz et al. (1999) employed the Matrix Language Framework (MLF) model and suggested that aphasic patients code-switched more often. The more significant amount of code-switching provided by the aphasic speakers may be due to their more dependence on the two languages after brain damage.

The results of the present study reveal the similarities and differences of code-switching in how neurological healthy bilingual speakers and bilingual aphasic patients code-switched.

Qualitative Similarities. This study revealed that the bilingual aphasic patients who can only access their first language generated code-switching patterns which are very similar in the quality to those produced by healthy controls. Both groups code-switched more on lexical words than on function words. This result is comparable with Wei (2002). They often used Mandarin nouns such as xiaopengyou 'children', beibao 'back bag', xiaotou 'thief', xiaoguo 'dog', mama 'mother', didi 'brother', erzi 'son', and nongfu 'farmer' in Taiwanese contexts. Therefore, the code-switching found in Taiwanese-Mandarin bilingual aphasic patients who can only access their first language cannot be considered as an atypical response since this pattern was found in the healthy bilingual speakers' speech data, too.

Language shift. The study showed that the code-switching patterns generated by the healthy bilingual speakers are different in two languages. Those healthy controls did not produce any code-switching in the Mandarin tasks; however, they code-switched on 120 words in the total 4037 words in the Taiwanese tasks. This result is compatible with Bhat and Chengappa's (2003) study since all the participants in the present study had used Mandarin actively in their adult life, and in Taiwan, the dominant language which was defined as a majority language or official language is Mandarin. When the healthy bilingual speakers narrated in their first language (Taiwanese), they code-switched much more frequently. In contrast, when they narrated in the dominant language/official language (Mandarin), they did not code-switch at all. The code-switching words they used in the Taiwanese context are the frequent-used words and have no equivalent translations in Taiwanese. This may indicate a language shift phenomenon which means after a certain period the second language takes over the first language. The active use of a second language over a long period of adulthood could result in that language becoming more accessible. This language shift phenomenon may have resulted from the reliance on metalinguistic knowledge since the second language (Mandarin) was learned formally and the second language 
was the language of instruction and people are not schooled in their native language, especially when the native language is a spoken dialect.

$\mathbf{L 1}$ or the dominant language recovers better. In the present study, WL and HQ's native language was less well recovered, but in contrast, LQ and XS's native language recovered better than their second language. Aglioti et al.(1996) reported a patient, E.M., who recovered her L2 (Italian) earlier and better than her L1(Venetian) and suggested that selective recovery patients may use the language learned in formal sets by conscious application of formal rules in order to recover a language mastered in natural learning sets without any conscious strategy. Also, Paradis (1994) suggests that both native and other languages may rely on implicit memory systems and explicit memory systems. The only difference is the various degrees that the mother tongue and the later-learned languages depend on implicit memory and explicit memory systems. The mother tongue may be more dependent on the implicit memory system, and the later-learned languages may rely more on explicit memory systems. He further explained that the mother tongue acquired early in life was highly automatized and was mainly used through unconscious procedures. In contrast, the later-learned languages are usually used by consciously applying grammatical rules. Therefore, according to the assumptions of Paradis (1994), Aglioti et al. (1996) suggested that the selective recovery bilingual aphasic patient E.M's L2 recovered better than L1 may be due to lesions of the left basal ganglia, which is part of the implicit memory system and mainly affects the most automatized language.

In addition, by looking back at cases about multilingual aphasia recovery patterns published over the end of the $19^{\text {th }}$ century and early $20^{\text {th }}$ centuries, Paradis (2009) has provided an account for the various language recovery pattern in bilingual aphasic speakers by using the differential roles of declarative and procedural memory. $\mathrm{He}$ assumes that the degree of recovery of some patients' native language was slower than a language that was learned formally later because they seem to have a greater amount of metalinguistic knowledge to rely on. $\mathrm{He}$ further hypothesised that patients only rely more on declarative knowledge when '(1) the second language was learned formally or (2) the second language was the language of instruction, and the patient was not schooled in his or native language, especially when the native language is a spoken dialect' (Paradis 2009, p.172).

However, the language background of all the patients in the present study shows that their native language was Taiwanese and they all started to learn Mandarin at school when they were seven or eight years old. Additionally, although nearly 75 percent of people in Taiwan speak Taiwanese, there was no unified writing system for Taiwanese. As a result, it was surprising that $L Q$ and XS's native language recovered better than their second language. Hence, the better recovery in aphasic patients' mother tongue may due to the lesions in the different areas of the brain. However, the aim of the present study was to provide an overview of Taiwanese-Mandarin bilingual aphasic speaker's code-switching behaviours; thus, the additional researches on the correlation of brain lesions and the recovery patterns need to be done in the future.

Code-switched more on verbs. Three out of four selective recovery aphasic patients produced a greater percentage of code-switching on verbs than on nouns. This pattern was not found in the healthy bilingual aphasic patients since the number of code-switching on nouns is two and a half times than that on verbs in Taiwanese contexts. This result indicates the differences of code-switching on content words between selective recovery patients and the healthy adults and may result from their inability of producing verbs. The difficulties of producing verbs for those aphasic patients may due to the 'mapping between word and referent is more transparent for concrete nouns than it is for verbs' (Gentner, 2006. pp.546). When patients put much more efforts on dealing with the semantics of verbs, this may take up more of their resources while they were producing speech, which in turn leads to a reduction in their ability to suppress the not-in-use language. Therefore, they may experience more difficulties in the inhibitory mechanism.

\section{CONCLUSION}

This study aims to research into whether the Taiwanese-Mandarin bilingual aphasic patients with the selective recovery pattern lose the knowledge of the inaccessible language or the control of the languages they spoke. 
The code-switching behaviours observed in the present study show that the healthy bilingual adults did not code-switch in L2 but L1 and this may be due to the language shift in their life. The increased amount of codeswitching observed in the four bilingual aphasic patients indicates that the patients did not lose the knowledge of the inaccessible language but the control of the languages they spoke. Furthermore, this may indicate their reliance on two languages as a compensatory strategy in order to enhance communicative effectiveness. The bilingual aphasic patients whose L2 recovered better show the effects of the dominant language which means that they relied more on metalinguistic knowledge.

\section{REFERENCES}

1. Abutalebi, J., \& Green, D.W. (2007). Bilingual language production: The neurocognition of language representation and control. Journal of Neurolinguistics, 20, 242-275.

2. Abutalebi, J., Rosa, P.A. D., Tettamanti, M., Green, D.W., \& Cappa, S. F. (2009). Bilingual aphasia and language control: A follow-up fMRI and intrinsic connectivity study. Brain \& Language, 109, 141-156.

3. Aglioti, S., Beltramello, A., Girardi, F., \& Fabbro, F. (1996). Neurolinguistic and follow-up study of an unusual pattern of recovery from bilingual subcortical aphasia. Brain, 119, 1551-1564.

4. Albert, M. L., \& Obler, L.K. (1978). The bilingual brain: Neuropsychological and neurolinguistic aspects of bilingualism. London, Academic Press.

5. Bhat, S., \& Chengappa, S. (2003). Code switching in Hindi-English and Kannada-English bilinguals. Paper presented in National Seminar on Multilingualism in India, Osmania University, Hyderabad, India.

6. Bhat, S., \& Chengappa, S. (2005). Code switching in normal and aphasic Kannada-English bilinguals. In J.C. Kara, T. McAlister, K. Rolstad \& J. MacSwan (Eds.), Proceedings of the 4th International Symposium on Bilingualism (pp.306-316). Somerville, MA: Cascadilla Press.

7. Chee, M. W. L., Tan, E.W.L., \& Thiel, T. (1999). Mandarin and English single word processing studied with functional magnetic resonance imaging. Journal of Neuroscience, 19, 3050-3056.

8. Chengappa, S., Daniel, K. E.., \& Bhat, S. (2004). Language mixing and switching in Malayalam-English bilingual aphasics. Asia Pacific Disability Rehabilitation Journal, 15(2), 68-76.

9. Fabbro, F. (2001). The bilingual brain: cerebral representation of languages. Brain \& Language, 79(2), 211222.

10. Gentner, D. (2006). Why verbs are hard to learn. In K. Hirsh-Pasek, \& R. Golinkoff, (Eds.) Action meets word: How children learn verbs (pp. 544-564). Oxford University Press.

11. Green, D. W. (1986). Control, activation, and resource: A framework and a model for the control of speech in bilinguals. Brain \& Language, 27, 210-223

12. Green, D. W. (1998). Mental control of the bilingual lexico-semantic system. Bilingualism, Language and Cognition, 1, 67-81.

13. Green, D. W., \& Abutalebi, J. (2008). Understanding the link between bilingual aphasia and language control. Journal of Neurolinguistics, 21, 558-576.

14. Grosjean, F. (1982). Life with two languages. Cambridge, Cambridge University Press. 
15. Grosjean, F. (1985). Polyglot aphasics and language mixing: a comment on Precman (1984). Brain \& Language, 26(2), 349-355.

16. Grosjean, F. (2001). The bilingual's language modes. In J. Nicle (Eds.), One Mind, Two Languages: Bilingual Language Processing (pp.1-22). Massachusetts, Wiley-Blackwell.

17. Goodglass, H., \& Kaplan, E. (1972). Boston diagnostic aphasia examination. Boston: Lea and Ferbirger.

18. Gürel, A. (2004). Selectivity in L2-induced attrition: A psycholinguistics account. Journal of Neurolinguistics, $17,53-78$.

19. Huang, S. F. (1993). Language, Society and Ethnic Identity. Taipei, Crane Publishing Co.

20. Hyltenstam, K. (1995). The code switching behavior of adults with language disorders with special reference to aphasia and dementia. In L. M. Milory, \& P. Muysken (Eds.) One Speaker Two Languages: crossdisciplinary perspectives on code-switching (pp.302-343). Cambridge, Cambridge University Press.

21. Klein, D., Milner, B., Zatorre, R.J., Zhao, V., \& Nikelski, J. (1999). Cerebral organization in bilinguals: a PET study of Chinese-English verb generation. Neuroreport, 10, 2841-2846.

22. Junque, C., Vendrell, P., Vendrell-Bruce, J.N., \& Tobena, A. (1989). Differential recovery in naming in bilingual aphasics. Brain and Language, 36, 16-22.

23. Kubler, C. (1988). Code-switching between Taiwanese and Mandarin in Taiwan. In R. L. Cheng, \& S. F. Huang (Eds.) The Structure of Taiwanese: A Modern Synthesis (pp.263-283) Taipei, Crane Publishing Co.

24. Lorch, M., and Barriere, I (2002). Pitres's two remarkable cases: Pure agraphia (1884) and Polyglot aphasia (1895). Advances in the neurolinguistics of bilingualism: essays in honor of Michel Paradis. F. Fabbro. Udine, Italy, Forum Press: 193-205.

25. Lorch, M. (2007). Bilingualism and memory: early 19th century ideas about the significance of polyglot aphasia. Cortex, 43, 658-666.

26. Lorch, M. (2009). Multiple languages, memory and regression: an examination of Ribot's Law. Aphasiology, 23, 643-654.

27. Menn, L., \& Obler, L. K., Ed. (1990). Agrammatic Aphasic: A cross-language narrative sourcebook. Amsterdam, Benjamins.

28. Muñoz, M. L., Marquardt, T.P., \& Copeland, G. (1998). A comparison of code switching patterns of aphasics and neurologically normal bilingual speakers of English and Spanish. Brain \& Language, 62(2), 249-274.

29. Paradis, M. (1977). Bilingualism and aphasia. In H. Whitaker \& H. A. Whitaker (Eds.) Studies in Neurolinguistics, 3 (pp.65-121). New York, Academic Press.

30. Paradis, M. (1983). Readings on aphasia in bilingual and polyglots. Montreal, Marcel-Didier.

31. Paradis, M. (1985). On the representation of two languages in the brain. Language Sciences, 7(1): 1-39.

32. Paradis, M. (1989). Bilingual and polyglot aphasia. In R.S. Berndt (Eds.) Handbook of neuropsychology: language and aphasia (v3, pp. 69-91). Amsterdam, Elsevier. . 
33. Paradis, M. (1993). Linguistic, psycholinguistic, and neurolinguistic aspects of 'interference' in bilingual speakers: The Activation Threshold Hypothesis." International Journal of Psycholinguistics, 9(2), 133-145.

34. Paradis, M. (1994). Neurolinguistic aspects of implicit and explicit memory: implications for bilingualism. In N. Ellis (ed.), Implicit and explicit learning of Second Languages (pp. 393-419). London: Academic Press.

35. Paradis, M. (1995). Aspects of bilingual aphasia. Oxford, Pergamon Press.

36. Paradis, M. (1997). The cognitive neuropsychology of bilingualism. In A. M. B. de Groot, \& J. F. Kroll (Eds.) Tutorials in Bilingualism: Psycholinguistic Perspectives (pp. 331-354) .New York, Psychology Press.

37. Paradis, M. (1998). Language and communication in multilinguals. In B. Stemmer \& H. A. Whitaker (Eds.) Handbook of neurolinguistics (pp. 417-430). San Diego, CA, Academic Press.

38. Paradis, M. (2009). Declarative and procedural determinants of second languages. Amsterdam, Philadelphia, John Benjamins Publishing Company.

39. Pearce, J. M. S. (2005). A note on aphasia in bilingual patients: Pitres' and Ribot's laws. European Neurology, $54,127-131$.

40. Perani, D., Dehaene, S., \& Grassi, F., Cohen, L., Cappa, S.F., Dupoux, E., Fazio, F., \& Mehler, J. (1996). Brain processing of native and foreign languages. Neuroreport, 7, 2439-2444.

41. Perecman, E. (1984). Spontaneous translation and language mixing in a polyglot aphasia. Brain and Language, 23, 43-63.

42. Pitres, A. (1895). Aphasia in polyglots. Readings on aphasia in bilinguals and polyglots. M. Paradis. Montreal, Didier: 26-49.

43. Ribot, T. A. (1882). Diseases of the Memory: An Essay in the Positive Psychology. New York, NY: D. Appleton and Company. Available at https://archive.org/details/diseasesofmemory00ribo/page/80 Accessed February 10, 2017.

44. Sasanuma, S., Kamio, A., \& Kubota, M. (1990). Agrammatism in Japanese: Two case studies. L. Menn, \& L. K. Obler (Eds.) Agrammatic aphasia: a cross-language narrative sourcebook (pp. 1225-1264). Amsterdam, Banjamins.

45. Scoresby-Jackson, R. (1867). Case of aphasia with right hemiplegia. Edinburgh Medical Journal, 12, 696-706.

46. Wei, L. (2002). The Bilingual Mental Lexicon and Speech Production Process. Brain and Language, 81, 691707.

\section{Data Availability (excluding Review articles)}

The data that support the findings of this study are available from the corresponding author upon reasonable request 


\section{Conflicts of Interest}

The author declared that: (i) no support, financial or otherwise, has been received from any organization that may have an interest in the submitted work; and (ii) there are no other relationships or activities that could appear to have influenced the submitted work. 